\title{
Quality Assessment on the Translation of Professional Translators
}

\author{
Rudy Sofyan ${ }^{1}$, Bahagia Tarigan ${ }^{2}$ \\ \{rudy@usu.ac.id'1 , bahagia1@usu.ac.id²\} \\ ${ }^{12}$ Faculty of Cultural Sciences, University of Sumatera Utara Medan, Sumatera Utara, Indonesia
}

\begin{abstract}
A function-based TQA model was developed last year emphasizing text function as one of the quality aspects needed to be assessed. However, the accuracy of this model in assessing the translation quality has not yet been examined. This study aims at finding out the accuracy of applying the functionbased TQA model in assessing the translation quality. This is a descriptive study taking 15 professional translators as the participants who were asked to translate a news item text from English into bahasa Indonesia. The data were collected using Translog and were analyzed using a content analysis method. The results of data analysis indicate that the function-based TQA model is accurate in assessing the translation quality of professional translators. The results imply the possibility of reducing subjectivity and relativity in TQA. It is concluded that the function-based TQA model works well in assessing the quality of translation. In addition, the results suggest a further comprehensive and systematic study on how the function-based TQA model can reduce such problems in TQA.
\end{abstract}

Keywords - Function-based TQA model, translation quality assessment, assessment problem

\section{Introduction}

Translation quality gets more concerns in translation studies since the increasing role of translation in this current era. However, the issue of quality continues to be debatable, especially in defining the term "quality" as it may refer to "good", "satisfactory" or "acceptable" translation [1]. Therefore, a number of studies have been conducted to find out the nature of quality in translation [2], [3]. Those studies were conducted due to different views of translation which leads to different concepts of translation quality, and ultimately results in different ways of assessing it [2]. One of the possible answers to the question 'what is a good or acceptable translation' is that a good translation should be as accurate as possible, and a translation should never be read like a translation [4]. This answer, however, is still unable to satisfy people's curiosity about the meaning of the term "quality" since accuracy in this context is still relative. Thus, instead of using the term "good" or "accurate", many scholars agree to use the term either "pragmatically adequate" [2] or "functionally appropriate" [5] to represent the meaning of quality. Having obtained the general notion of translation quality, other studies 
have explored and developed a more representative and comprehensive model to assess the translation quality (e.g. [6]-[11]). Representative, in this context, can be understood as the representation of meaning, the precise choice of words, acceptable grammar to the target language (TL); meanwhile, comprehensive can be understood as the availability of sufficient explanation of aspects of the quality of the translation being assessed. Therefore, a representative and comprehensive TQA model is expected to assess the translation quality in a holistic way. Several previous TQA models were developed on a holistic basis (e.g. [6], [12]); nevertheless, the models do not contain a detailed distinguishing explanation of each quality level, which is extremely required to objectively grade the translation quality level.

Although those previous studies have proposed new models in TQA, subjectivity, and relativity continue to be present in assessing translation quality. One of the efforts to reduce such issues was done by Sofyan \& Tarigan [10] who developed a translation quality assessment (TQA) model based on the text function applicable in the TL, known as function-based TQA model. The model provides a comprehensive explanation for each level of quality of the translation results suggested in the previous studies on TQA ([1], [7], [11], [13]-[16]) for the purpose of minimizing relativity and subjectivity in TQA. Although the function-based model is developed from a systematic study on translation quality, the model cannot be said to be a truly representative and comprehensive model until it is tested. The most appropriate way of testing the function-based TQA model is through a systematic study. This study aims at finding out the accuracy of applying the function-based TQA model in assessing the translation quality.

\section{Method}

This study was conducted using a descriptive method taking the quality assessment on English-Indonesian translation done by professional translators as the central phenomenon that needs investigation. The data were the translated texts produced by 15 professional translators and the results of translation quality assessments using the function-based TQA model done by 3 raters. The professional translators were selected using such criteria as (i) having more than two-year experience in professional translation practices, (ii) having a formal education on translation studies, and (iii) being an Indonesian native speaker. The raters were translation scholars having experience in translation practices.

The data were collected using a translation test. The professional translators were asked to translate a news item text entitled "Facebook unveils its plan for oversight board" (downloaded from https://www.bbc.com/news/technology-49735795) from English into bahasa Indonesia. Translog was used as the instrument to collect the data. The translated texts were analyzed using a content analysis method. The results of the translation were assessed using the functionbased TQA model. The results were then categorized into the translation quality level developed in Waddington's TQA model [6] as shown in Table 1. The quality level of each translation was analyzed to describe the results of the TQA qualitatively.

Table 1 Translation quality level [6]

\begin{tabular}{ccc}
\hline Level & Degree of task completion & Mark \\
\hline Level 5 & Successful & $81-100$ \\
Level 4 & Almost completely successful & $61-80$ \\
Level 3 & Adequate & $51-60$ \\
Level 2 & Inadequate & $31-50$ \\
Level 1 & Totally inadequate & $11-30$ \\
\hline
\end{tabular}




\section{Results and Discussion}

The assessment done by the three translation scholars (raters) was intended to get the objective results of the TQA on the translation done by professional translators. Each of the raters has assessed the translation using a scoring rubric provided in the function-based TQA model and a translation quality level in the Waddington's TQA model. Based on the results of the quality assessment, the quality level of the translation done by the professional translators is divided into two categories: successful and almost completely successful translation. The quality of the translated texts is quite satisfactory because all of them are above the adequate level; nevertheless, only 4 translated texts successfully conveyed the ST meaning into the TT. The data presented in Table 2 show the quality of translation done by professional translators.

Table 2 The results of TQA using a function-based TQA model

\begin{tabular}{cccccc}
\hline Participants & \multicolumn{3}{c}{ TQA Results } \\
\cline { 2 - 5 } & $1^{\text {st }}$ Rater & $2^{\text {nd }}$ Rater & $3^{\text {rd }}$ Rater & Average & Quality Level \\
\hline Professional A & 69 & 72 & 70 & 70.33 & Almost completely successful \\
Professional B & 62 & 64 & 65 & 63.67 & Almost completely successful \\
Professional C & 70 & 72 & 72 & 71.33 & Almost completely successful \\
Professional D & 88 & 90 & 87 & 88.33 & Successful \\
Professional E & 70 & 71 & 70 & 70.33 & Almost completely successful \\
Professional F & 79 & 79 & 78 & 78.67 & Almost completely successful \\
Professional G & 74 & 76 & 77 & 75.67 & Almost completely successful \\
Professional H & 77 & 80 & 81 & 79.33 & Almost completely successful \\
Professional I & 90 & 91 & 89 & 90.00 & Successful \\
Professional J & 85 & 87 & 86 & 86.00 & Successful \\
Professional K & 86 & 87 & 85 & 86.00 & Successful \\
Professional L & 71 & 72 & 71 & 71.33 & Almost completely successful \\
Professional M & 77 & 79 & 78 & 78.00 & Almost completely successful \\
Professional N & 68 & 68 & 67 & 67.67 & Almost completely successful \\
Professional O & 72 & 72 & 70 & 71.33 & Almost completely successful \\
\hline
\end{tabular}

The results of the assessment for each translated text done by the three raters presented in Table 2 indicate that the highest score of TQA is given to the translation done by Professional I, with the average score of 90; and the lowest score is given to the translation done by Professional B, with the average score of 63.67. In addition, the TQA results also indicate an accurate quality assessment as they do not show significantly different scores. In other words, the TQA results submitted by the three raters are reliable, following the inter-rater reliability [17]. Such accurate TQA results are mainly caused by a well-designed scoring rubric used in the TQA model. The use of clearly distinguishing quality descriptions for each quality aspect provided in the model rubric is the factor that can minimize the possible relativity and subjectivity found in TQA. The results of TQA on the translation done by Professional A, for example, can be described as "the translation containing several inaccuracies, unsuitable equivalents, inconsistent thematic progression, and minor grammatical errors which do not have an influence on TL readers' understanding". Such a description is obtained from the detailed TQA results as described in Table 3. 
Table 3 Quality description of the translation done by professional A

\begin{tabular}{|c|c|c|c|}
\hline \multirow[t]{2}{*}{ Rater } & \multirow{2}{*}{$\begin{array}{l}\text { Quality } \\
\text { Aspects }\end{array}$} & \multicolumn{2}{|r|}{ Professional A } \\
\hline & & Scores & Descriptions \\
\hline \multirow[t]{6}{*}{$1^{\text {st }}$ Rater } & $\mathrm{AC}$ & 21 & $\begin{array}{l}\text { Containing several inaccuracies with no influence on } \\
\text { TL readers' understanding }\end{array}$ \\
\hline & $\mathrm{FE}$ & 16 & $\begin{array}{c}\text { Containing few unsuitable equivalents for specialized } \\
\text { vocabulary }\end{array}$ \\
\hline & TS & 13 & Reflecting no major translation errors \\
\hline & $\mathrm{TF}$ & 11 & $\begin{array}{l}\text { Almost meeting the text function with inconsistent } \\
\text { thematic progression }\end{array}$ \\
\hline & GS & 8 & Containing minor grammatical errors \\
\hline & Total & 69 & \\
\hline \multirow[t]{6}{*}{$2^{\text {nd }}$ Rater } & $\mathrm{AC}$ & 22 & $\begin{array}{c}\text { Containing several inaccuracies with no influence on } \\
\text { TL readers' understanding }\end{array}$ \\
\hline & $\mathrm{FE}$ & 17 & $\begin{array}{c}\text { Containing few unsuitable equivalents for specialized } \\
\text { vocabulary }\end{array}$ \\
\hline & TS & 13 & Reflecting no major translation errors \\
\hline & $\mathrm{TF}$ & 12 & $\begin{array}{l}\text { Almost meeting the text function with inconsistent } \\
\text { thematic progression }\end{array}$ \\
\hline & GS & 8 & Containing minor grammatical errors \\
\hline & Total & 72 & \\
\hline \multirow[t]{6}{*}{$3^{\text {rd }}$ Rater } & $\mathrm{AC}$ & 21 & $\begin{array}{c}\text { Containing several inaccuracies with no influence on } \\
\text { TL readers' understanding }\end{array}$ \\
\hline & FE & 16 & $\begin{array}{l}\text { Containing several unsuitable equivalents for } \\
\text { specialized vocabulary }\end{array}$ \\
\hline & TS & 13 & Reflecting no major translation errors \\
\hline & $\mathrm{TF}$ & 12 & $\begin{array}{l}\text { Almost meeting the text function with inconsistent } \\
\text { thematic progression }\end{array}$ \\
\hline & GS & 8 & Containing minor grammatical errors \\
\hline & Total & 70 & \\
\hline
\end{tabular}

Notes: $\mathrm{AC}=$ Accuracy; $\mathrm{FE}=$ Finding equivalents; $\mathrm{TS}=$ Translation skill; $\mathrm{TF}=$ Text function; GS = Grammar and TT style

The descriptions of each aspect of translation quality displayed in Table 3 show that, despite the different scores given by the three raters, there is no different quality description found in the translation of Professional A. Following the quality level in the TQA model [6], all of the raters agree that the translation done by Professional A falls into the category of "almost completely successful" translation task. This means that Professional A needs a harder effort to make his translation successful by reducing both grammatical or equivalent errors. The translation in (1) is the extract of the work done by Professional A.

ST : Facebook has unveiled its plan to create an independent "oversight" board to make decisions over how the network is moderated.

TT : Facebook telah meluncurkan rencananya untuk membuat suatu dewan "pengawasan" independen untuk membuat beberapa keputusan atas bagaimana jaringan dimoderasi. (1)

The TT contains several inaccuracies in terms of equivalence, one of which is the translator's decision to use the word "meluncurkan" as the equivalent of "unveiled". The ST word "unveiled" originally means "disclosing something that used to be covered or hidden"; meanwhile, its equivalent (meluncurkan) does not completely convey its meaning as it is 
related to the act of announcing, informing, or declaring. The other inaccuracy is the use of "dimoderasi" as the equivalent of "moderated", which is mainly motivated by a borrowing technique applied by the translator. However, the word "dimoderasi" is not widely used in the TL; therefore, there should be an effort to find the more widely used equivalent such as "diperbaiki". In terms of grammar and style, the translation in (1) also has problems. Although the TT word "pengawasan" is equivalent in meaning with the ST word "oversight", it is not the right equivalent in this context. "Oversight" should be translated as the one carrying out the duty of oversight itself. Therefore, by relieving the SL style interference, the translation can be improved by writing "dewan pengawas independen". The other SL interference is also found in using "atas" as the equivalent of the ST word "over", resulting in an awkward TL structure. The right equivalent for the word "over" in this context is "terhadap".

The results of qualitative analysis on the translation done by Professional A imply that context plays a very important role in deciding the right diction [18]-[20], and the translation would be impossible without contextual considerations [21]. An established equivalent is often denied due to the influence of the context.

Furthermore, the TQA results presented in Table 2 show that the translation of Professional I is the one with the best quality. Its quality is described as "the accurate translation containing skillfully chosen equivalents corresponding to the TT social function written in an acceptable TL structure and style". The detailed descriptions are provided in Table 4.

Table 4 Quality description of translation done by professional I

\begin{tabular}{ccccc}
\hline Quality & \multicolumn{3}{c}{ Raters } & Descriptions \\
\cline { 2 - 5 } Aspects & $1^{\text {st }}$ & $2^{\text {nd }}$ & $3^{\text {rd }}$ & The original message has been conveyed completely to TL readers \\
\hline AC & 27 & 27 & 27 & Equivalents have been chosen skillfully \\
FE & 23 & 23 & 22 & The translator demonstrates creative solutions to translation \\
TS & 18 & 18 & 17 & problems \\
& & & & The TT generally meets the text social function \\
TF & 13 & 14 & 14 & There is almost no grammatical error \\
GS & 9 & 9 & 9 & Successful translation \\
\hline Total & 90 & 91 & 89 &
\end{tabular}

The TQA results presented in Table 4 indicate that all of the raters agree that the translation done by Professional I is a successful translation despite very few inaccuracies. One of such inaccuracies can be seen in (2).

ST : Users affected will be allowed to state their case in a written statement,

TT : Para pengguna yang merasakan dampak tersebut akan diizinkan untuk menyatakan kasus mereka melalui pernyataan tertulis, (2)

The translation in (2) demonstrates the translator's creative solution to the translation problems. The obvious one is shown in finding the best equivalent of the ST word "affected" which literally means "dipengaruhi" in the TL. However, the translator decides to give more description in order to provide more comprehensive and representative equivalent by writing "yang merasakan dampak tersebut" as the equivalent of "affected". Another good solution is the translator's decision to use the word "melalui" as the equivalent of the ST word "in", which literally means "dalam" in the TL. Although the word "melalui" has its established equivalent in the SL (i.e. "through"), the use of such equivalent in this context shows a creative choice of equivalent. Despite a good solution, the TT also contains less accurate equivalent. Using "menyatakan" as the equivalent of "state" in this context is not the best decision. The word "menyatakan" is specifically used in a speech mode, while the context shows that the case is delivered in a written mode (written statement), indicating the meaning incompatibility of the 
elements constructing the clause. As the case is stated in a written statement, the best equivalent of the word "state" in this context is "menyampaikan", equivalent with the English word "deliver".

The results of the data analysis show that the function-based TQA model works well in assessing the quality of translation done by professional translators. The TQA results represent the same level of quality of translation although assessed by different raters. Consequently, this TQA model is possibly helping to reduce the subjectivity [11] and relativity ([22], [23]) in TQA, the two problems usually encountered in TQA. The factor that enables reducing such a problem is the presence of clearly distinguishing sub-aspects of translation quality in the TQA model; in other words, the function-based translation model helps to assess the translation quality as objectively as possible. In this model, each of the quality sub-aspects is provided with a quality description. The use of quality description at each sub-aspect controls the raters ${ }^{6}$ subjectivity in TQA as they would not completely be free to give scores for the assessed translation. Although subjectivity and relativity are two common problems in TQA, their presence cannot be eliminated because they contribute to arts in translation quality assessment. TQA is done by human, and is presumably impossible to be done by machine; therefore, small disparities in the TQA results show that there must be human freedom in its process. This becomes the reason to provide score range in every quality level of translation assessment and the reason to argue that a successful translation must not be scored 100 because there will never be a perfect equivalence in translation, and the term assumed equivalence is used instead [24].

However, the model needs to be further developed for the absence of the overall quality level of the translated text. In order to facilitate such weakness, a TQA model developed by Waddington [6] is used. The model classifies the translation quality level into five categories: successful, almost completely successful, adequate, inadequate and totally inadequate translation. Nevertheless, this quality level needs does not fully support the scoring rubric provided in the function-based translation model. In other words, the function-based TQA model should be completed with a translation quality level that corresponds to each quality aspect description provided in the model.

\section{Conclusion}

Based on the results of the study, it is concluded that the function-based TQA model works well in assessing the quality of translation done by professional translators. The almost similar results of translation submitted by the three raters are the evidence of accurate assessment of translation quality using the function-based TQA model. Nevertheless, despite its accurate assessment of translation quality, a more comprehensive study on how it reduces subjectivity and relativity in TQA needs to be conducted. This is due to the fact that the raters' subjectivity is still found in the TQA results. As it only provides quality in the form of scores, this model needs to be developed by including the overall quality level of the assessed translated text. In addition, this study only focuses on one text type, i.e. news item; hence it is suggested for other researches interested in studying the TQA model to use this function-based TQA model in assessing other different text types. Furthermore, the results of the study contribute to the professionalism in translation in terms of encouragement to professional translators to always develop their language and translation skills because the scores obtained by the professional translators in this study are not quite satisfactory. 


\section{Acknowledgments}

The authors would like to thank the Research Institute of the University of Sumatera Utara for funding this research under the TALENTA 2019 Research Grant.

\section{References}

[1] M. Williams, "The Application of Argumentation Theory to Translation Quality Assessment," Meta, vol. 46, no. 2, pp. 326-344, 2001.

[2] J. House, Translation quality assessment. A model revisited. Tubingen: Narr, 1997.

[3] J. House, Translation quality assessment: Past and present. London: Routledge, 2015.

[4] P. Newmark, About Translation. Philadelphia: Multilingual Matters, 1991.

[5] C. Schaffner, "From 'Good' to 'Functionally Appropriate': Assessing Translation Quality," Curr. Issues Lang. Soc., vol. 4, no. 1, pp. 1-5, 1997.

[6] C. Waddington, "Different Methods of Evaluating Student Translations: The Question of Validity," Meta, vol. 46, no. 2, pp. 311-325, 2001.

[7] M. Williams, Translation quality assessment: An argumentation-centered approach. Ottawa: University of Ottawa Press, 2004.

[8] C. V. Angelelli, "Using a rubric to assess translation ability: Defining the construct," in C. V. Angelelli \& H. E. Jacobson (eds.), Testing and assessment in translation and interpreting studies. Amsterdam: John Benjamins Publishing Company, pp. 13-48, 2009.

[9] G. Medadian and D. N. Mahabadi, "A Summative Translation Quality Assessment Model for Undergraduate Student Translations: Objectivity Versus Manageability," Stud. About Lang., Vol. 26, pp. 40-54, 2015.

[10] R. Sofyan and B. Tarigan, "Developing a Holistic Model of Translation Quality Assessment," Adv. Soc. Sci. Educ. Humanit. Res., vol. 254, no. CONAPLIN 2018, pp. 266-271, 2019.

[11] M. Almutairi, "The objectivity of the two main academic approaches to TQA: An Analytical study," SKASE J. Transl. Interpret., Vol. 11, no. 2, pp. 79-95, 2018.

[12] M. Nababan, A. Nuraeni, and Sumardiono, "Pengembangan model penilaian kualitas terjemahan," Kaji. Linguist. dan Sastra, Vol. 24, no. 1, pp. 39-57, 2012.

[13] F. Farahzad, "Testing achievement in translation classes," in C. Dollerup \& A. Loddergard (eds.), Teaching Translation and Interpreting, Amsterdam: John Benjamins, pp. 271-278, 1992.

[14] M. Williams, "A holistic-componential model for assessing translation student performance and competency," Mutatis Mutandis, Vol. 6, no. 2, pp. 419-443, 2013.

[15] M. Madkour, "The Application of Functional Linguistic Models for Assessing Quality of Translation: A Descriptive Analytical Study," Int. J. English Linguist., vol. 6, no. 6, pp. 87-117, 2016.

[16] H. Khanmohammad and M. Osanloo, "Moving toward Objective Scoring: A Rubric for Translation Assessment," J. English Lang. Stud., Vol. 1, no. 1, pp. 131-53, 2009.

[17] J. W. Creswell, Educational Research: Planning, Conducting, and Evaluating Quantitative and Qualitative Research. Boston, MA: Pearson Education, Inc., 2012.

[18] A. K. Melby and C. Foster, "Context in translation: Definition, access and teamwork," Int. J. Transl. Interpret. Res., vol. 2, no. 2, pp. 1-15, 2010.

[19] J. House, "Text and context in translation," J. Pragmat., vol. 36, pp. 338-358, 2006.

[20] M. Manfredi, Translating text and context: translation studies and systemic functional linguistics, vol. 1. Bologna: Centro di Studi Linguistico-Culturali (CeSLiC), 2008.

[21] T. F. Doyle, "The Role of Context in Meaning and Understanding," Potsdam University, 2007.

[22] B. Mossop, Revising and Editing for Translators. New York: Routledge, 2014.

[23] N. Nae, "Markedness, Relevance and Acceptability in Translation," Forum Int. Dev. Stud., Vol. 26, pp. 103-114, 2004.

[24] A. Pym, Exploring translation theories. New York: Routledge, 2009. 